\title{
LIFEINSURE: CHOOSING A PRODUCT ADMINISTRATION SYSTEM TO MANAGE THEIR PRODUCT LIFECYCLE ${ }^{1}$
}

Joseph Bromer, Head of IT Solutions Delivery at LifeInsure Emerging Markets, deliberated on a challenge that he had just been given. TIBCO, a vendor supporting ObjectStar, notified LifeInsure that support for the application would cease at the end of 2017. ObjectStar was the Product Administration System (PAS) system used by LifeInsure. The ObjectStar platform was called Alpha and was used in over 200 applications. There were a number of risks, which added more pressure including the scarcity of skills and an aging workforce, but the key risk related to this was the lack of ongoing support.

LifeInsure PLC was a leading insurance company in South Africa. Long-term insurers formed a big part of the financial sector in the economy of the country. Most insurance companies like LifeInsure were dependent on the global economic growth which influenced the growth of their organizations. South Africa's economy showed decline at the end of 2015. This impacted LifeInsure's performance. An aging PAS contributed to slowing down product delivery and increased risk. Alpha was business critical to the organization. The Alpha platform was divided into Alpha 1, 2 and 3. Alpha 3 was the main PAS system which was used for their main product range within Retail Affluent South Africa. These platforms execute various functions and integrate with various systems internally and externally.

TIBCO formally proposed an option of migrating ObjectStar to their Business Works suite, including an automated coding port into Java. While TIBCO proposed migration as an option, noting that Java was trendy, LifeInsure had to make a very important decision. Should LifeInsure go with the solution of automatically porting, or should they explore other options, particularly for the core business applications? Whatever decision they made, it had to be future-fit for the organisation. Looking at these challenges, how should Joseph Bromer respond to this? In order to make an informed decision, it was clear that Joseph Bromer had to initiate an investigation into the PAS system that had been used by the business and the processes that underpinned this technology. It was important that the decision moved towards supporting the revised business strategy. The revised strategy was to move towards a center of excellence operating model. The product innovation department was working on a refreshed product strategy for the 3-core product ranges, which were: the protection range, savings range and the income range. Elements of these demanded that the right solution be sourced. These elements would allow for efficiencies enablement, giving rise to simpler product maintenance processes, service processes, sales processing, etc.

\footnotetext{
${ }^{1}$ Copyright (C) 2017, Muma Case Review. This case was prepared for the purpose of class discussion, and not to illustrate the effective or ineffective handling of an administrative situation. Names and some information have been disguised. This case is published under a Creative Commons BY-NC license. Permission is granted to copy and distribute this case for non-commercial purposes, in both printed and electronic formats.
} 


\section{Life Insurance}

Life insurance was an agreement between customers and a company, in which the company guaranteed payment in compensation for a clearly defined loss. The customer agreed to pay a premium until the event occurred. An example was when a death occurred of the covered life--the company paid the proceeds to the beneficiary or estate of the covered life. Life insurance not only provided guarantees in the event of a clearly defined loss, but it also had a component of bonuses of investments built into it. The value of this type of policy increased over a period of time as bonuses or positive growth were added. When the event occurred, the sum assured, as well as all bonuses, were paid out at the time the loss occurred. LifeInsure offered investment, savings, life assurance, asset management, banking and property, and personal insurance in South Africa, Africa, Europe, the Americas and Asia. In South Africa, LifeInsure was one of the largest insurance companies in the industry, having been in business for many years.

\section{The Life Insurance Industry in South Africa}

LifeInsure was headquartered in South Africa, a country located at the southern tip of the African continent. South Africa was a diverse nation which consisted of different cultures and religions; it had 11 official languages. Until 1991, the Apartheid regime was in effect: a government-instituted dispensation which had forcibly separated the country's races and, in practice, treated the non-white population as second- or third-class citizens. In 1991, Apartheid was officially abolished and in 1994 the first universal franchise elections made South Africa a democratic country. A 2016 census reported a population of 55,653,654 million people in the country. Exhibit 1 reflects the population makeup of the country. At the end of 2015, the unemployment rate was extremely high at 26.7\%. Exhibit 2 reflects the employed and unemployed population in South Africa as of the beginning of 2016. An average working household earned a combined salary of R17422 (US \$1,245.09). A household was made up of all adults working and contributing towards the household expenses. Exhibit 3 represents only the formally employed sector's average wages.

In South Africa, long-term insurers formed a big part of the financial sector in the economy. South Africans were more inclined than most countries towards buying insurance. This stemmed from an African cultural perspective where it was obligatory to provide for any event of unforeseen circumstances. Cost in burials when a death occurred had always been high. The cultural and social pressures for extravagant funerals pushed many Africans into taking out funeral policies and providing for their families after death. The average cost of a funeral in South Africa in 2016 was in the region of \$857.60 (R12 000) while cremations would start at about \$571.73 (R8 000). This was due to people customizing funerals and cremations according to their special requirements. They did not always have access to large amounts of cash and by paying a small premium towards a LifeInsure policy and being assured in the event of death, they were covered for the cost towards the funeral of their choice. Funerals could also include rented tents and gazebos, rented cars, rented accommodation for distant family members attending the funeral, catering and expensive coffins. When considering a burial, a tombstone was also needed, making burials more expensive than cremation. African culture had a concept of sending off the deceased in a dignified way, and also of providing for your loved ones after death. Therefore by accommodating the customary needs of the customers, it benefited the organization as well as their customers. This explained in part why South Africa had the largest life insurance penetration rate in Africa, and the second largest in the world.

The insurance industry in South Africa was regulated by the Financial Services Board (FSB). The regulation of the insurance industry was necessary to make sure that when promises were made to customers, the organization delivered on their promises. This was normally in the form of monetary payouts. Some of the largest insurance companies in the world were based in South Africa, of which LifeInsure was one. As part of the regulation of the industry, when an advisor or broker gave advice to 
customers on their financial portfolio, they had to be accredited, or have the necessary knowledge to do so. The Financial Services Board (FSB) took this seriously and offered consumers protection against unlawful business practices in South Africa. By having the necessary regulations in place, a healthy insurance market in the country was created for both parties.

Most insurance companies were dependent on global economic growth, which influenced the growth of their organization. South Africa's economy showed decline at the end of 2015, which resulted in factors like the increase in interest rates. This had a knock-on effect on food prices, which resulted in less disposable income in the general household expenditures. When pressure was applied on the disposable income of consumers, it resulted in policies going off the books, consumers withdrawing from their savings, and fewer customers taking up new business risk policies or investments. The economy was also influenced by political factors in the country. Political unrest caused uncertainty in the markets, resulting in investors withdrawing their South African investments.

\section{Lifelnsure}

LifeInsure operated mainly in South Africa and also has been one of the largest financial services providers in South Africa for well over 100 years. They were listed on the stock exchange under the FTSE 100 companies. Hence, LifeInsure played an important part in South Africa's economy. One of LifeInsure's priorities was to grow the economy of Africa, focusing on South Africa from a local drive. Their main business focus was financial planning, providing a wide range of savings plans and insurance coverage for individuals and businesses. The company had around US $\$ 400$ billion funds under management and had a customer base of almost 20 million at the time of the case.

Being in business for so many years, LifeInsure had a well-established, well recognized brand which was driven by their Group's core internal values based on integrity, respect, accountability and pushing beyond boundaries. LifeInsure employed more than 50,000 employees. Even though located all over the world, staff was bound to the core values of the group. LifeInsure applied the five pillars of responsible business, namely:

- Responsible to customers

- Responsible investment

- Responsible to employees

- Responsible to communities

- Responsible to environmental management

As an organization, they operated in different market segments. It was extremely important for such a big organization to balance the risk with its funds under management, hence a key ingredient was to have good corporate governance throughout the organization and good operating practices. Their risk appetite was continuously assessed to make sure it minimized risk and optimized capital efficiency, making sure that they never exceeded their risk tolerance. There were many different regulations within the country that govern their businesses, and it was of utmost importance for the group to comply with these laws. Risk management and corporate governance were extremely important. By implementing a risk management framework and corporate governance, LifeInsure ensured that business alignment and processes were in place that contributed to strategic alignment within IT and their operation decisions. LifeInsure was aware of new risks which threatened their business or customers. Upgrading of technology 
was one aspect ensuring that the organization was vigilant, and continually strengthening their controls as aging technology could pose risk to the business operations.

LifeInsure also played a significant role in the social development of communities in South Africa, in order to grow the communities and the people of South Africa. Skills development was a key initiative in this regard. This assisted the country in moving towards becoming a world-class country. The important areas of focus in social development have been: education, sports, arts and culture.

Joe Mobane, Chief Executive Officer of LifeInsure Emerging Markets, and other delegates represented LifeInsure at the 2016 World Economic Forum in Davos. This afforded the group the opportunity to meet with the best world leaders, and allowed the organization to gain some insight into future global trends. Some of the key trends that were discussed were:

- A volatile global economy

- Artificial intelligence

- Climate change

- The sharing economy

- New risks

There was no doubt that the trends listed above affected LifeInsure as a business, and their customers' wellbeing, directly. A clear message was communicated that all stakeholders needed to collaborate and work together in order to restore the financial well-being across the world.

A tough economic climate in 2016 presented challenges, but also enormous opportunities for LifeInsure. Due to South Africa's socio-political pressures at the end of 2015, many of the markets which LifeInsure operated in were affected. This was due to the stressful financial circumstances of their customers. South Africa was also experiencing severe drought conditions and this placed extra pressure on the economy of South Africa. External economic factors also affected LifeInsure, for example, the slowdown in China's market growth, the interest rate hikes in the United States of America, and the drop in the oil prices at the time. These factors impacted heavily on LifeInsure's Global funds, and they put South Africa's equity markets under pressure. There was a move towards disrupting traditional industries and overturning conventional business models, and this also had an impact on how the financial services industry operated. All these influences forced the organization to ponder on whether their projects were going to support their business effectively. Another factor that caused self-questioning was the global technology evolution, with the world moving towards an "Era of Digitization"--which had implications on the way organizations responded to and managed their IT estate (see Exhibit 4). The business strategy was aimed primarily at enabling rapid growth, but in order for this to be achieved, IT implications and assumptions had to be considered. LifeInsure had serious considerations to make. Declining competitiveness of their retail product offering, especially in the product protection market, and difficulties for customers to convert between their Mass Foundation Cluster products and Retail Affluent product ranges, were cause for concern. This put extra pressure on the competitive advantages that LifeInsure had in the market.

\section{Background}

LifeInsure serviced different market segments in South Africa. Intermediate product offering ranges were serviced via LifeInsure Emerging Markets, which encompassed the majority of LifeInsure's customers. Note that there were more segments in LifeInsure (see Exhibit 5). Each of these segments had its own IT strategy and servicing strategy, which made it difficult for customers to convert between the product ranges. Each segment administered its business on a separate Product Administration System (PAS). 
A Product Administration System (PAS) was used to manage and maintain the product lifecycle offered by LifeInsure for a particular customer or business.

LifeInsure Emerging Markets had decided on a product strategy to move towards more holistic product offerings to customers. Moving towards a product strategy in terms of a center of excellence operation model, and working towards offering a refreshed product strategy for 3-core product ranges and towards a single offering, it emerged that the way in which they administered their products via technology needed to align with the product strategy.

\section{Alpha Platform}

The Alpha platform runs on ObjectStar and was supported by a company called TIBCO. This core administration platform was used in LifeInsure Emerging Markets for Retail Affluent risks and savings businesses. The Alpha platform was divided into 3 separate platforms, namely Alpha 1, 2 and 3. Alpha platforms executed various functionalities, including user front end, reinsurance, calculation of premiums, fund switches, bank details validation, medical fees payments, etc. It was used for risk and savings businesses within South Africa as well as in other countries such as Namibia, Swaziland and Mexico. Alpha 1 and 2 were closed for new business, but existing business products continued to be maintained on these two platforms. Alpha 3, the main platform used, was still open to new business and was integrated with other systems internally, like Oracle financials, Disbursements, Front end applications, Correspondence, Automated Work Distribution (AWD), Bizagi Business Process Management (BPM), Group Client System (GCS), Enterprise Service Bus (ESB), Inter-Operability (IOP), Portfolio View Builder (PVB) and Enterprise Data Warehouse (EDW). It was also integrated with external systems-- $3^{\text {rd }}$ party systems like banks, Association for Savings and Investment South Africa (ASISA), South Africa Revenue Services (SARS) and reinsurers. This system hosted many knowledge areas which were used by many departments within LifeInsure (see Exhibit 6).

The challenge LifeInsure had was that TIBCO gave LifeInsure advance notice that they were retiring ObjectStar technology. Software maintenance and support services formally ceased at the end of 2015, but paid for support extended into 2017, with a further extension request until 2020. Alpha 3's book of businesses was critical to LifeInsure's emerging markets. It had a total of new business volume of 350,000 policies per annum, with a total of 1.9 million customers as of 2015.

With the above announcement regarding ObjectStar, TIBCO made a formal proposal to LifeInsure to migrate ObjectStar to their Business Works suite. To facilitate this transition, an automated script would migrate the code, porting it into Java language. While TIBCO proposed migrations using a porting solution as an option, noting that Java was trendy, LifeInsure still wanted to continue to fully explore other options that were out there, particularly for the core business applications. The reason was that whatever option they chose, it had to be future-fit for the organization. At this point in time, LifeInsure was not necessarily looking for a "one size fits all” solution, but more to a long-term solution. Their key focus was maintaining and sustaining Alpha 3, as well as new product development to potential customers. Alpha 3 integrated with a whole host of other core systems (see Exhibit 7). A number of factors guided the organization in exploring new PAS options as well:

- Potential regulatory issues

- Sustainability of solution--in terms of cost as well as maintainability

- $\quad$ Cost of delivery

- $\quad$ Risk of delivery 
- $\quad$ Speed of delivery

- Digestion risk and management distraction

- Mix of skills required--business vs. technical--and their availability

- Impact on LifeInsure and their customers

- Impact on new business development

- Impact on current integration

LifeInsure operated in a complex environment (see Exhibit 8). Whatever option was pursued, it had to make business sense for the organization going forward.

\section{Evaluation of Potential Options}

In order for LifeInsure to make an informed decision, various options were under consideration. The objective of this review was to ascertain the best suitable options available to LifeInsure in response to TIBCO withdrawing support for ObjectStar by the end of 2017. A high-level assessment of available options was conducted before making an informed decision. Looking at each of the applications affected by ObjectStar and assessing the most appropriate option (or options) for these applications was important to the organization.

\section{First Option (The Default Option)}

This would be a “do nothing” type approach with appropriate risk management and containment, keeping the application and maintaining the applications as they were, using the ObjectStar environment and mitigating the support risk in some way. Evaluations under consideration were:

- LifeInsure could accept the risk of keeping their applications running on ObjectStar beyond the end of the support period, without TIBCO support. This appeared as an attractive option, but extremely risky to the operation. The ObjectStar code would eventually become legacy and resources would become scarce. ObjectStar was currently highly reliable, but the upgrading and maintenance of the database would become an issue. If support could be extended, this would have been an attractive option, but the likelihood was seen as low. Continuing without support was viewed as viable in some cases, but risky overall.

- LifeInsure could procure access to the ObjectStar source code, and support and maintain the environment themselves; or LifeInsure could join other ObjectStar customers, who could collectively procure access to the ObjectStar source code, and support and maintain the environment themselves. The option of procuring or buying the licence for ObjectStar would also be a consideration. This would have allowed the business to continue with very little business impact. The risk in going alone into doing this was high, but doing it with other companies alongside LifeInsure would mean that the risk would be shared. The complexity around this was the onerous effort to find an organization that would be willing to share and manage the language.

- LifeInsure could negotiate with TIBCO to gain extended support, or convince other ObjectStar customers to negotiate support for ObjectStar beyond the current timeline. This would mean that LifeInsure would defer the problem further. The issue remained that ObjectStar was a legacy code and not used by many organizations. Finding a way to extend TIBCO support was viewed as attractive, but successful delivery of such an agreement was deemed unlikely. Hence, the question was whether to pursue these options or not.

Were any of the above options viable to the organization, especially if there were other organizations of the same size and complexity as LifeInsure in similar situations? The impact on the business would be 
minimal, but would this mean that the organization was only deferring the problem indefinitely? Skills scarcity would eventually become an issue. Another question that the organization had to answer was if it was imperative for the business to change based on the business strategy. The next consideration was:

\section{Evaluating the Option of Porting Business Works Suite into Java Language.}

Using the TIBCO porting proposed option, this would have converted the ObjectStar logic into Java. This would have been executed within their Business Works suite. This option appeared to be attractive. Java language was future-fit and appeared viable. LifeInsure had a very good relationship with TIBCO, built over many years. Having a good relationship with a vendor was vital to achieving success. TIBCO offered this option to LifeInsure, where they undertook to do the migrating of the code via an autoconverted tool, with the input and planning from LifeInsure. LifeInsure would have to invest a significant amount of money and time into this option. With this option, it would not necessarily be a $100 \%$ successful migration; it would present challenges. Issues like customized complex functionality would arise, and this code would automatically be excluded from the conversion process.

A separate undertaking had to be looked at to convert this code. The regression testing had revealed a huge amount of effort to be employed. Without the benefit of auto-scripting, it would be an enormous task to execute and manage. Auto-scripting did not exist in the business at the time. Even with the most careful planning, serious disruption to the business operations would be likely. The cost around this option would also need to be considered carefully. Even though TIBCO had undertaken to do the migration, training and up-skilling of staff needed to be planned. The cost around the staff's learning additional skills was unclear at the time. Maintenance of the code that would be left behind after migration had to be evaluated. The overall business risk had to be carefully evaluated as well. How often had platform porting, coupled with a language change, happened with major success? The regulators would want a view of the amount of risk associated with this option before granting their approval. Given the platform work that had been undertaken for the rest of Africa at the time, LifeInsure also considered the possibility of accessing synergies of a platform approach, in particular around the PAS replacement which had taken place in Africa.

\section{Evaluation of Synergy of Internal System Used within LifeInsure.}

LifeInsure was not new at implementing a retail PAS. They implemented Oracle's OIPA in Nigeria in 2014. Noting that Nigeria's product requirements were different to South Africa, the new PAS platform had to meet the South African requirements. It was important to note that there were major differences between South Africa and the rest of Africa when it came to selecting a PAS system. Some of these differences were:

- The complexity of the South African retail products was much higher than in the rest of Africa. Advanced investment fund functionality was more relevant for SA savings products than for Africa, for example, unitization, bulk purchasing, investment recon, etc.

- SA IT architecture philosophy was more "componentized” than Africa, for example: external calculation engine, URE, reinsurance management system, etc.

- Scale of decision was much more complex in South Africa. The existing book was much larger compared to Africa. 
- Considering the risk appetite of the organization: The group's appetite for exposure to technology/supplier/support risk in South Africa was much lower than in Africa.

However, there were similarities between the two entities as well:

- Both environments needed delivery capability to support the managing of their products ranges.

- Both environments needed to support multiple countries, currencies and regulatory environments (for example Namibia and Swaziland on current South African retail systems).

Due to all of the above, the option of re-use of the Africa platform was eliminated. This was mainly due to different requirements when looking at considerations for acquiring a new PAS for South Africa. A different set of criteria had to be met. The Alpha product needs and knowledge areas had to be taken into consideration (see Exhibit 6).

\section{The Replacement Option.}

This option entailed replacing the application with a packaged application solution, either new or existing, but recognizing that the functionality would be likely to be a different PAS. Options under evaluation would be:

- Replace the existing application with another existing application, rather than a new application in house. LifeInsure would have to source a team of programmers, business analysts, etc., to commit to this option. In LifeInsure, there would likely be a skills gap regardless. Whatever development language was chosen, the team must have a thorough understanding of the business processes and how to develop a new application. LifeInsure would have to maintain and improve the system as improvements and changes were required. This option would be a costly option, but would ensure that complete control of the application would be in-house. All those working with the application would have an in-depth knowledge of how it works. Customization and matching the exact business requirements would be possible. The advantage of this option would also be that the source code and final product would be owned by LifeInsure. This solution could provide LifeInsure with a better competitive advantage. Some disadvantages could be that it might be exorbitant to maintain and execute improvements to meet the business demands. Employing experts and retention of these employees might be costly.

- Replace applications with modern, package-based solutions with equivalent or perhaps enhanced functionality, and migrate data or customers onto new application. The advantage to this would be that the solution already existed and could readily be used by LifeInsure. The proficiency for a package system was readily available, normally from a proven vendor. Training would be given to staff. Most of the development and testing would be done by the vendor. This would result in excellent functionality. Maintenance would normally be given as part of the contract, and off-the shelf-packages were already fit to best practices. Vendors normally had a reliable track record of successful implementations. This would normally be the most cost-effective solution. Some disadvantages would be that the rights to the software were normally retained by the vendor. Customization of the functionality might be restricted. When sourcing a new PAS, certain aspects would have to be taken into consideration. These aspects include:

- Delivery Risk

- Architectural Fit 
- Speed of Execution

- Sustainability / Maintainability

- Solution Agility / Flexibility

- IT Operating / Delivery Model Fit

- $\quad$ Business Impact (during delivery)

- Customer Impact (during delivery)

- Cost to Deliver

- Cost to Maintain

- Flexibility of Commercial Model

- Ability to Meet Business Need (vs. today)

- Operational Risk

It was important to note that the value that the new PAS would add, versus the quality, needed to be measured against this consideration. Another important aspect of implementing a new PAS was sourcing the right delivery partner. The decision on the PAS solution delivery capability was normally tied to the PAS platform decision. The choices of implementation partner(s) for the PAS and overall transformations were not as dependent on the technology solution. Defining the roles and responsibilities of LifeInsure and the vendor was necessary. The initial approach to this was to look at possible vendors and packages on the market, shortlisting these candidates, assessing their strengths, and crafting a detailed Request for Proposal (RFP). These candidates would have to prove their ability to play in 3 key categories which would be: (1) the delivery of the solutions, (2) delivery strengths and expertise on the PAS, and (3) the ability to take joint responsibility for the overall transformation program.

Through this approach, candidates were shortlisted using an internal scoring and market research to assess their ability to provide a Request for Proposal (RFP). The Request for Proposal would consist of an invitation to vendors to elaborate on their offerings. The PAS vendor assessment criteria that were used were as follows:

\section{Policy Admin Platform}

- Ability to support complex and unique OM functionality

- Ability to support various regions \& products

- Platform flexibility--ease of integration

- Platform investment and roadmap

\section{Migration Ability and Approach}

\section{Implementation Approach}

- Ability to support parallel development and implementations

- Flexible / Global resource model

- Cost flexibility

- End to End implementation

\section{Fit for Purpose - (Technical and Implementation Partner)}

Looking at what LifeInsure's requirements were and what certain vendors offered, vendors were shortlisted and invited to respond to the RFP. These vendors were Bancs from TCS, (see Exhibit 9), ALIS from Sapiens (see Exhibit 10), Sonata from Bravura (Exhibit 11) and OIPA from Oracle (Exhibit 12). 
Selecting an appropriate vendor would require assessment of the feedback provided by these vendors. A key component of the whole transformation would be managing the migration from the legacy system to the new proposition. The complexity would be a major challenge.

\section{Migrating}

Part of this important consideration would be the requirement around migration. The migration process was the transfer of the business process IT resources to the targeted platform. It was important to understand that when considering the migration option, that whatever has been targeted needed to be from a business gaining perspective. The cost and the risk would determine the approach taken. With this in mind, an investigation had to be executed. The possible options were illustrated in a 4-based models illustration in Exhibit 13, and variation for moving the old legacy system's policy base to the targeted platform was looked at. The viability of an option had to be determined and a mixed option might be an option to consider. Migration would only be assessed once the organization agreed on the way forward.

\section{The 4-based model approach was as follows:}

\section{Manual customer triggered migration}

This would be a client-driven switch to the new retail proposition. It would entail that every client would instruct LifeInsure to cancel their existing contracts and request a new contract via the new business process. Tax implications and the long-term insurance act restrictions would affect these clients. There was a view that this could be intermediary driven, but over 400,000 of those customers were currently un-intermediated. LifeInsure would essentially be expected to re-contract and re-issue $1.7 \mathrm{~m}$ contracts to $1.2 \mathrm{~m}$ customers over a 3 to 4 -year period. While this would be an attractive option for some aspects of the book, one could not do this with $100 \%$ of the contracts. This would have placed the organization into an "unplanned" migration scenario. Practically speaking, would this be a viable option to go for?

\section{Policy migration and automatic upgrade}

Upgrading and converting polices to the new products: This would essentially move all LifeInsure's "legacy" policies into the new protection offering. This would have a number of challenges. Firstly, it would depend on whether LifeInsure was contractually allowed to convert all contracts to the new option. Secondly, would there not be significant margin erosion? Most customers would want to keep their existing premium, so the change in corresponding terms and benefits of the new product would need to be funded, and this would likely have a significant impact on the embedded value of the book.

\section{3a. Policy migration followed by a customer triggered upgrade (manual) \& 3b. Policy migration onto the target platform}

This would be a traditional lift-and-shift migration, which would bring technical challenges of creating the exact policy terms, conditions and features as the source platform. This, however, would create significant flexibility for LifeInsure. LifeInsure would have the option of running special offers to convert blocks of books post-migration, where it would make financial sense for them to move those customers, and where there was clear customer value. LifeInsure could also do premium reviews on those policies that were out of the guaranteed period.

Whatever decision would be taken around migration, LifeInsure would have to take the legal binding contract between customers and LifeInsure into account--and this played the most significant role in the choice that the organization would take. The risk appetite for migration would be significant to their business, and would have to be considered with precaution and with the necessary legal backing. Input from legal, product owners, business owners and legislators would have to be assessed. 


\section{The Decision}

While analysing the decision space, it was clear that more than one option existed. Information had to be assembled around what decision would be best for the organization: keeping the current application, porting it to the new proposed solutions by TIBCO, synergy amongst internal applications, or replacing it with a new solution. All of these options would have an important capability. LifeInsure had very complex environments, and different application types had been built in ObjectStar. ObjectStar was core and critical to the business operations. The option that would be chosen would have to be from a highquality perspective and have to add business value as well. Replacement or porting were the most viable options. Remaining within an unsupported environment could be considered high risk. No significant offhand solutions sprang to mind, therefore each option had to be explored.

Through observations some issues were uncovered and important criteria for this consideration were highlighted. How risky would the delivery be? How well would the change fit into the organization's architectural framework? Would the organization have to look at implementing a new architectural framework? Would the solution be available prior to the retirement of ObjectStar? Would the solution be sustainable and maintainable for the future? Would the solution's agility and flexibility fit into LifeInsure's world? More importantly, what would the business impact be? Would LifeInsure be able to meet the business needs and what value would it add?

The return on investment had to be justified as well as the operational requirements needing to be clearly met. It was important to take the risks and challenges into consideration when making these decisions. An important consideration that also needed to be assessed was the extent to which this level of change would constrain business over the period and how this would be managed. The proper selection of technology platforms and implementation partners would be imperative if a new PAS was selected. It was important to note that technology did not only drive the decision, but also the business strategy and the vision that LifeInsure had in going forward. LifeInsure had to start taking advantage of the opportunities in technology and maximizing on technological trends. Finally, the one major objective which LifeInsure needed to meet was to port or replace the PAS with an internal solution or with a new package of solutions. 


\section{Acknowledgements}

This case study was based upon work done by the transformation project team within LifeInsure. Special acknowledgements go to all the staff members at LifeInsure who assisted the authors in compiling the information used in this case study. Due to confidentiality, they also have to remain nameless.

\section{Biographies}

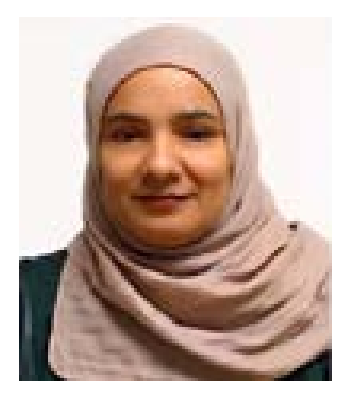

Kaasiefa Gasant has been a Lead Business Analyst since 2006. She is a part-time student at University of Cape Town working towards completing her BCom honors degree in Information Systems and will be graduating in November 2017. She has over 18 years work experience, holding a variety of different positions within the corporate sector. Kaasiefa is hardworking and self-driven. She has developed a passion for analysis, problem solving and software implementation.

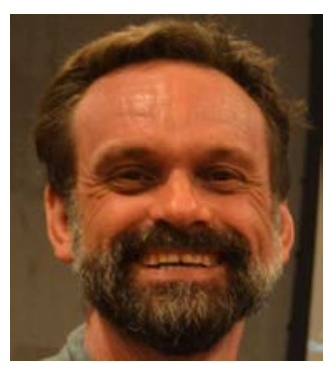

Jean-Paul Van Belle is a professor in the Department of Information Systems at the University of Cape Town and Director of the Centre for IT and National Development. His research areas are the adoption and use of emerging technologies in developing world contexts including mobile, cloud computing, open and big data. His passions are ICT4D - with a focus on emerging technologies as well as data for development (D4D) in an SDG context - and adoption of ICTs by small organizations. He has over 170 peer-reviewed publications including 25 chapters in books and about 40 refereed journal articles. He has been invited to give a number of keynote presentations at international conferences and holds an honorary professorship at Amity University. He currently supervises almost 20 Masters and PhD students and has graduated many more. Jean-Paul has active collaborations with researchers in India, UK, Ethiopia, Kenya and Mauritius. Research interests include: ICT for development (ICT4D); emerging technologies; data revolution and SDGs; ICT use by small organizations. 


\section{Exhibit 1: Population of South Africa}

\section{Population of South Africa as at 2016}

$\begin{array}{lr}\text { Provincial } & \\ \text { GAUTENG } & 13.4 \mathrm{M} \\ \text { KWAZULUL-NATAL } & 11.1 \mathrm{M} \\ \text { EASTERN CAPE } & 7.0 \mathrm{M} \\ \text { WESTERN CAPE } & 6.3 \mathrm{M} \\ \text { LIMPOPO } & 5.8 \mathrm{M} \\ \text { MPUMALANGA } & 4.3 \mathrm{M} \\ \text { NORTH UEST } & 3.7 \mathrm{M} \\ \text { FREE STATE } & 2.8 \mathrm{M} \\ \text { NORTHERN CAPE } & 1.2 \mathrm{M}\end{array}$

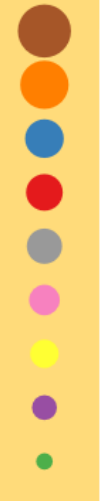

POPULATION

Total population

grew from 51770

560 in 2011 to 55

653654 in 2016

Source: http://www.statssa.gov.za/ 
Exhibit 2: Unemployment and Employed Levels within South Africa as of First Quarter 2016
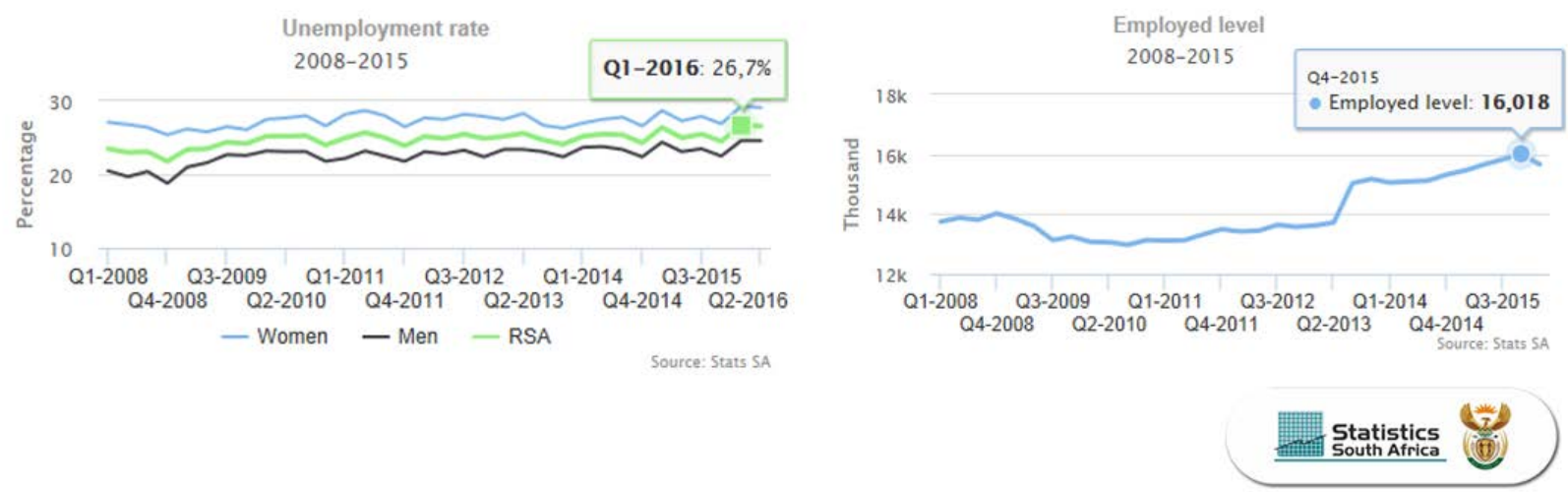

Source: http://www.statssa.gov.za/ 


\section{Exhibit 3: Average Wage Indicator Per Household}

SOUTH AFRICA AVERAGE MONTHLY GROSS WAGE

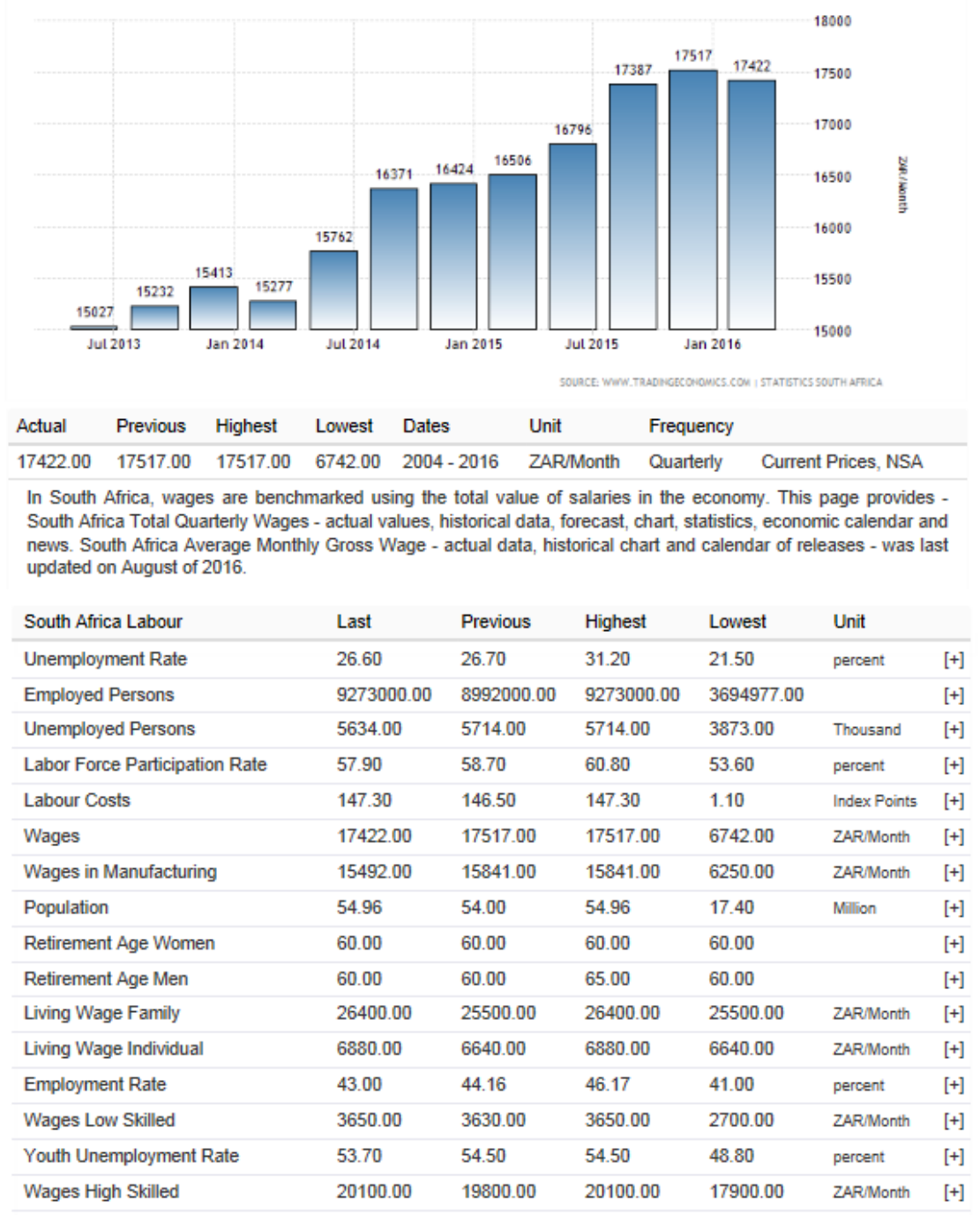

Source: https://tradingeconomics.com/ 


\section{Exhibit 4: Taming the Digital Dragon by Gartner}

Globally technology and its role have evolved and the world has entered into the "Era of Digitilization," with implications for the way organizations respond to and manage their existing IT

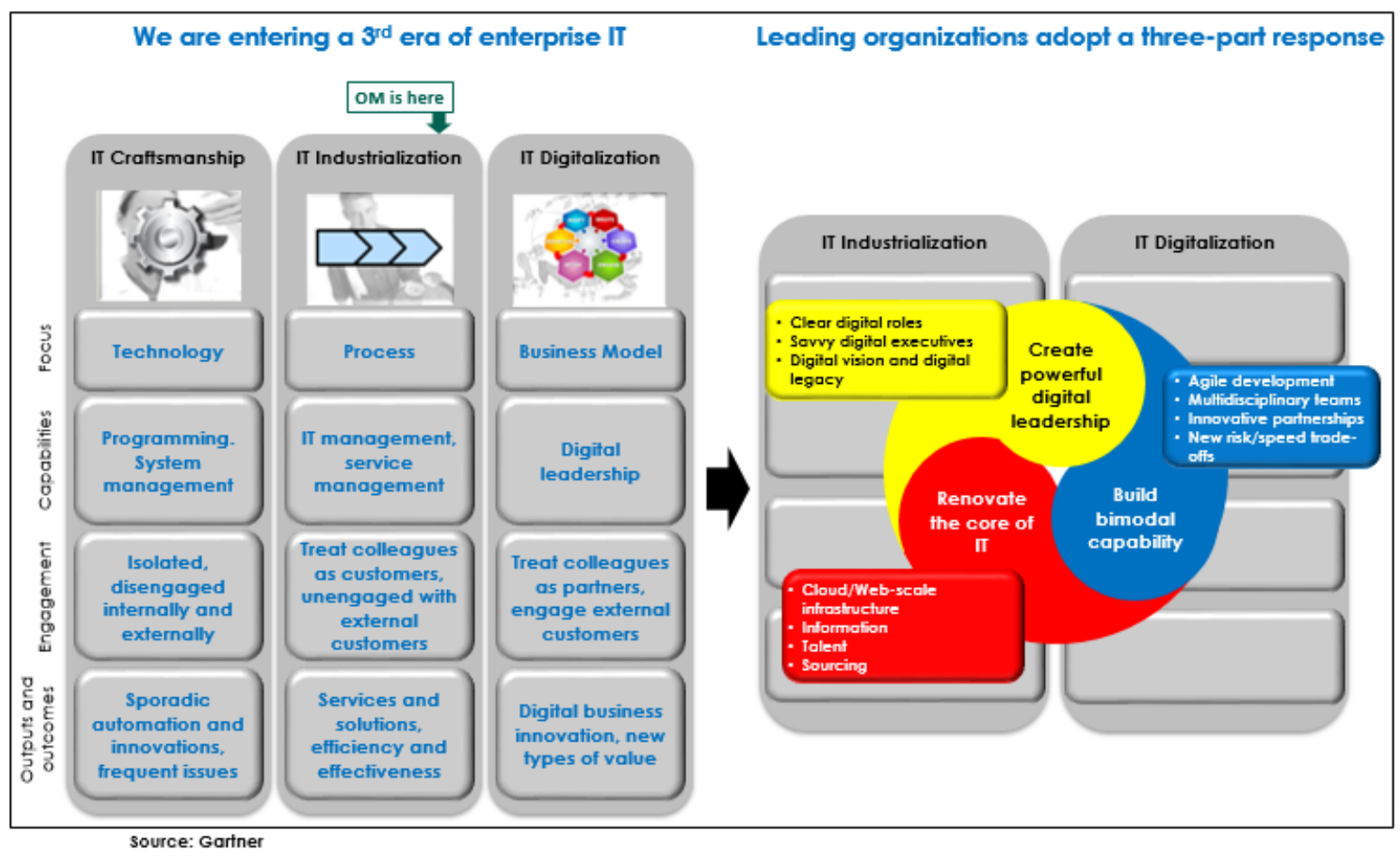

Source: https://www.gartner.com/imagesrv/cio/pdf/cio_agenda_insights2014.pdf 


\section{Exhibit 5: Target Operation Model}

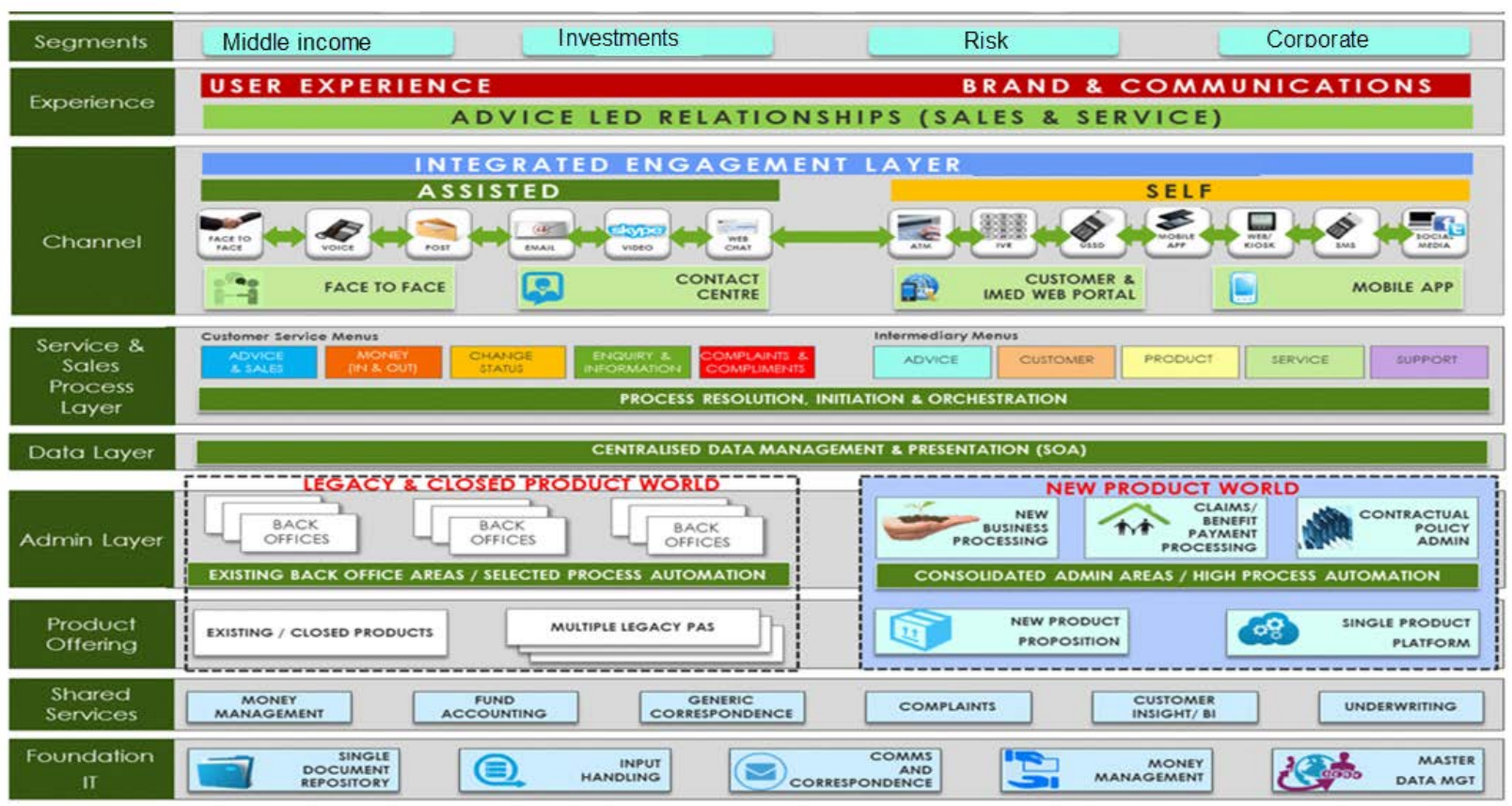

Source: Company internal website 
Exhibit 6: Alpha III Knowledge Model

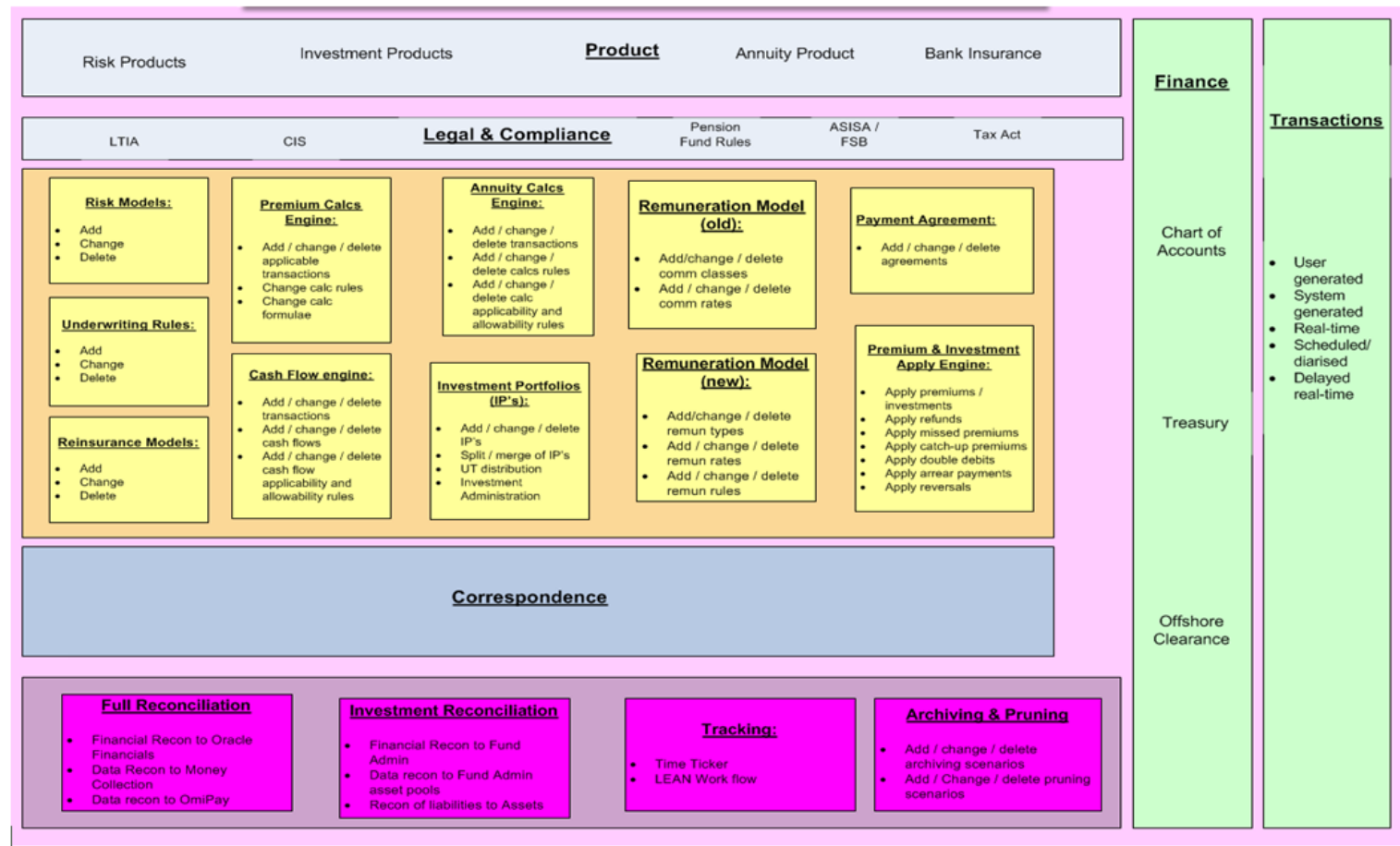

Source: Company internal website 


\section{Exhibit 7: Alpha III Interface Architecture}

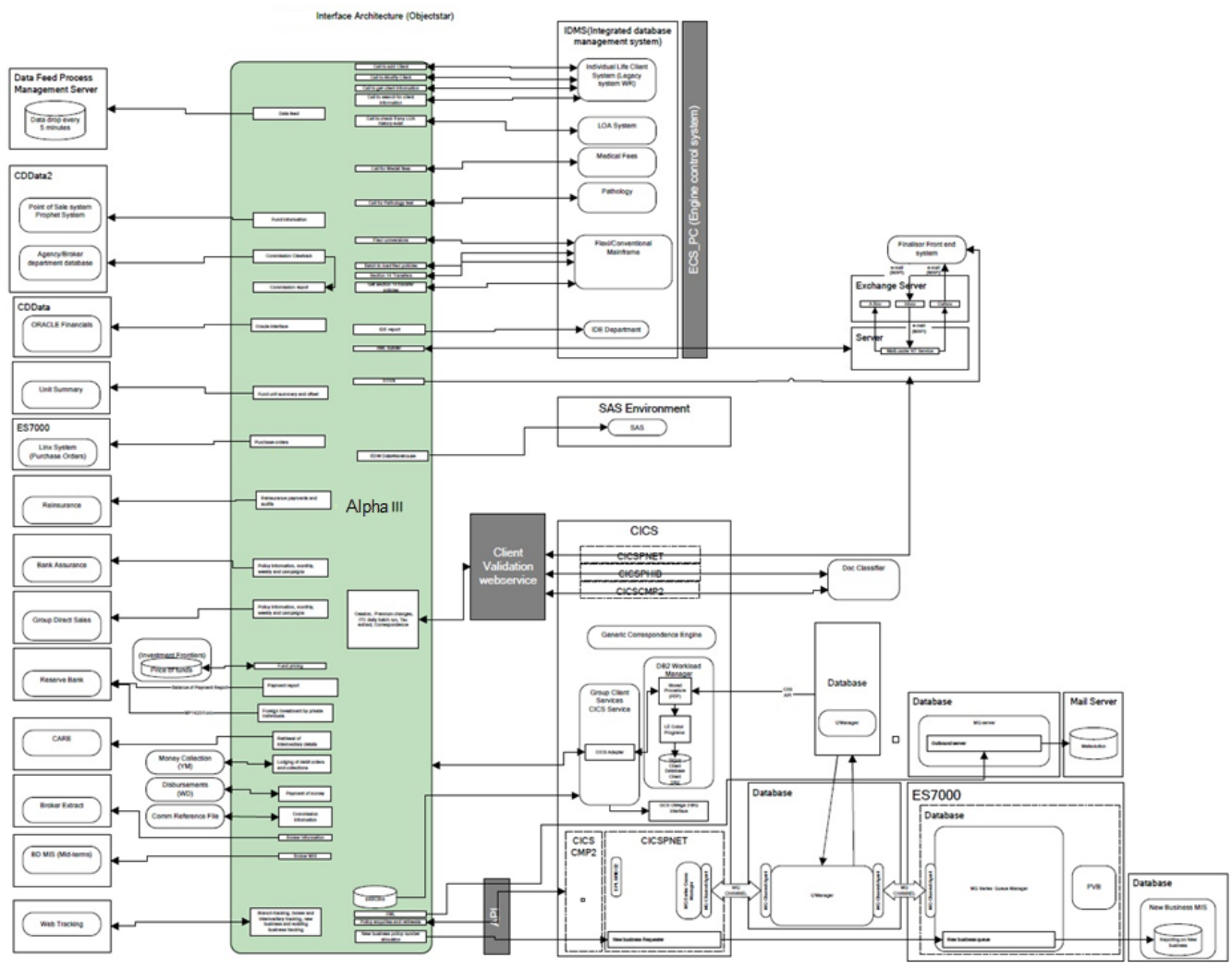

Source: Company internal website 


\section{Exhibit 8: High Level Model of Current Applications Used}

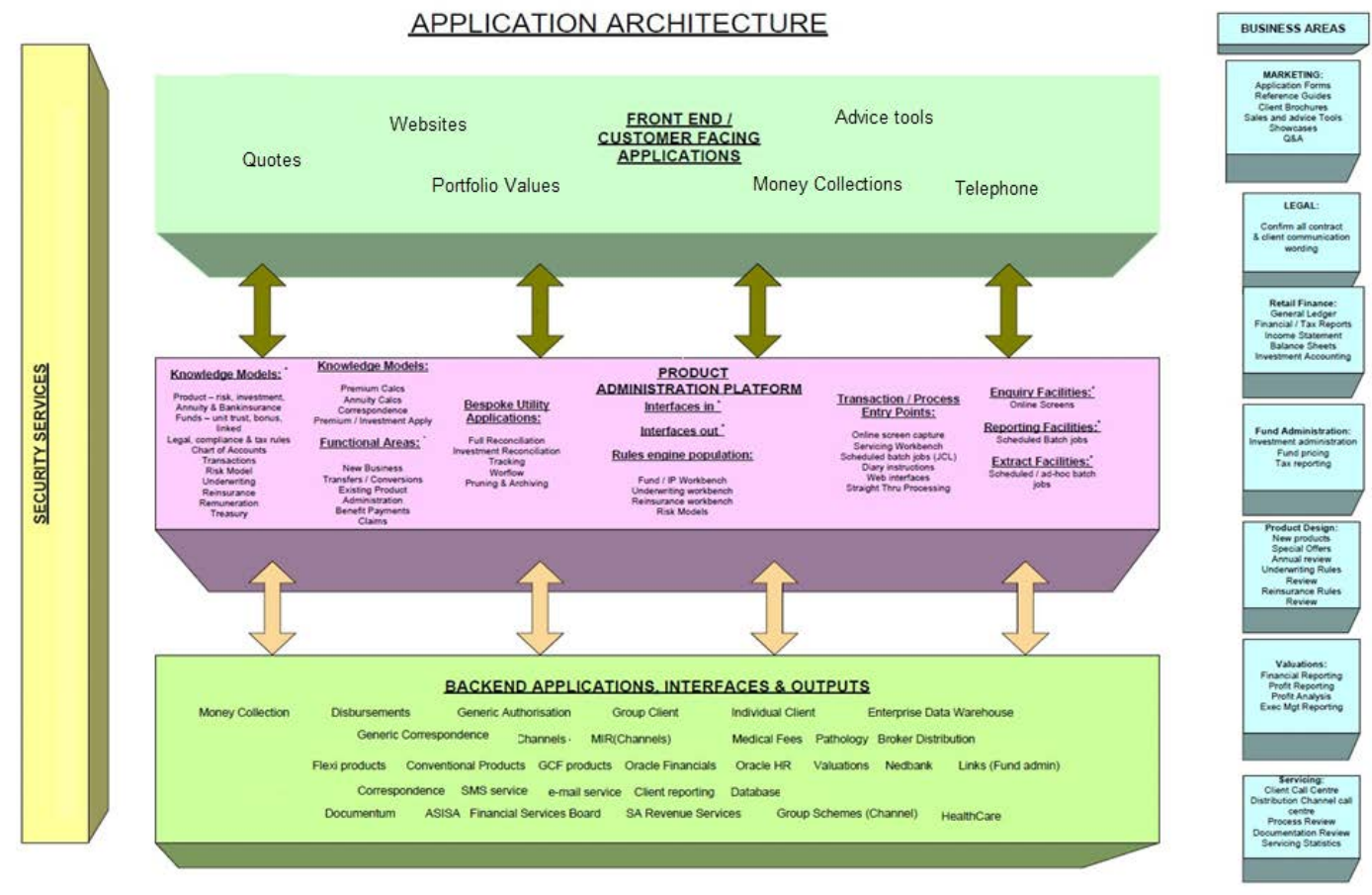

Source: Company internal website 


\section{Exhibit 9: TCS Bancs Insurance Solution}

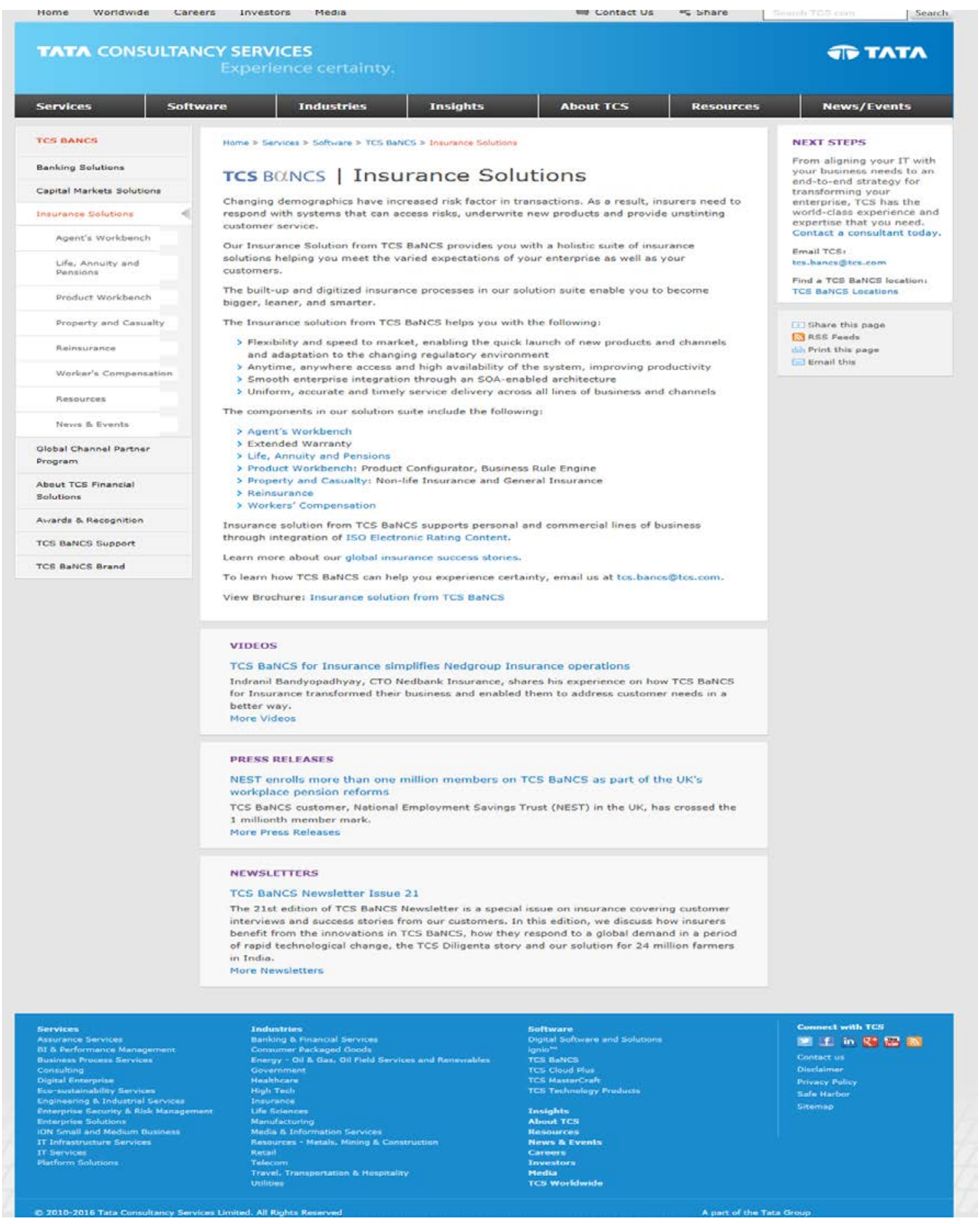

Source: https://www.tcs.com/ 


\section{Exhibit 10: Sapiens ALIS Insurance Solution}

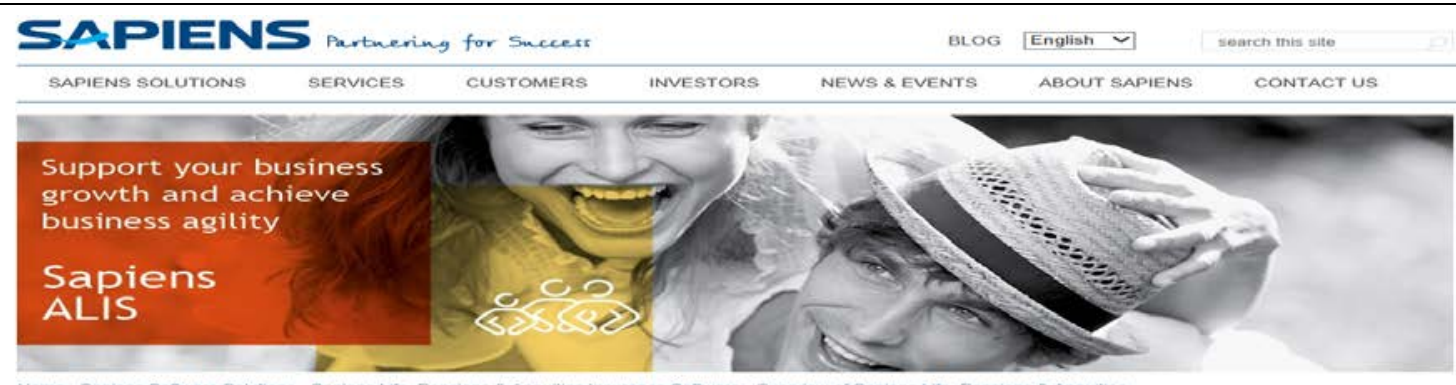

Home, Sapiens somware Solutions , Sapiens Lite, Pensions s Annuities insurance Somware,
Overview of Sapiens Life, Pensions \& Annuities

Sapiens ALIS is our flagship solution designed to enabte insurance carriers to quickly and efficiently address the chatlenges of a highty regulated and increasingly competitive marketplace. Our end-to-end, core solution suite supports the complete policy lifecycle across a wide variety of products in the life, pension, annuity and medical segments. Alis life insurance software uniquely combines functional maturity and robusthess gained through decades of gtobal success, vith cutting-edge innovation a

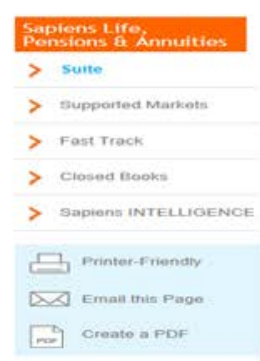

- $\rightarrow$ crato a rof

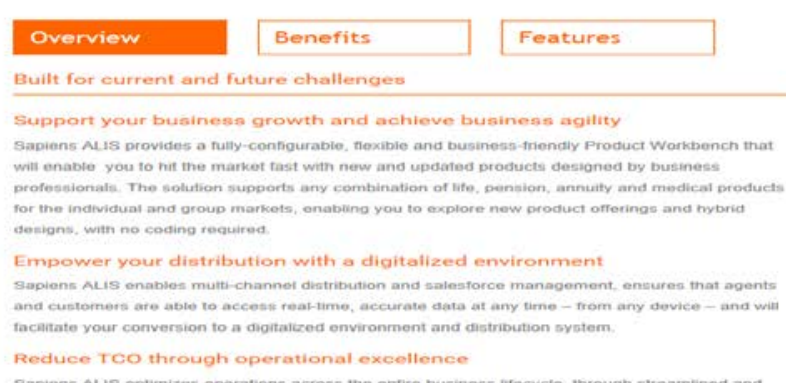

Sapiens ALIS optimizess operations acrons the entire business ufecycle, through streamtined and automated processess, straight-throush processing, workhow manogement and seamiess inteoration to market and regutatory changes, white applying strong self-sumciency capabiaties

Go global. go local

Supported by Saptens giona presence and teqionat insight, Sapiens ALIS it designed for muth. dimention and global operat

Sapiens ALIS in the Cloud

Sapiens ALIS - our core poticy administration swite tor the iffe insurance, annutities, pension.

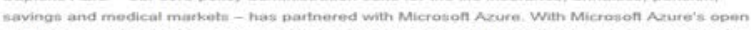

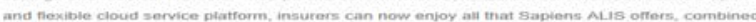
with the advantagen of the clouse

Chck here to downioad our cloud brochure.

Leam more on Sapiens ALIS Sollware Benentits Learn more on Sabiers AL. is Soltware Features More about Sapiens solutions for insurance soltware

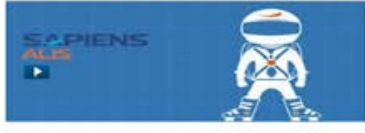

\section{ALIS Quick Links}

$>$ terochurel sapiens ALIS (E urope)

$>$ iBrochurol saptons Aus cuss

$>$ terochurel Sapiens ALis in the cloud

$>$ mhite Papen Orownth AND Con Savings $\mathrm{a}$

$>$ inm

$>$ Untographicj Digtalication's Massive Potential for inzurance Carmern fi

$>$ celont Report about MLIS in EMEA

$>$ [eBooks loTwenty Five: internot of

Things in 2025

$>$ touidel 11 Tip:

\section{ALIS Case Studies}

$>$ CFa (U.S.) emorges unitied on Sapiens

$>$ anohtarey (UK) - mion deares of functhonat bi out ot - the-box with Aus

$>$ Cotumbian Financial Group (U S) the and annuity

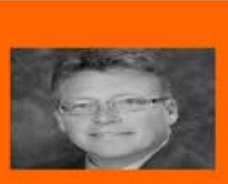

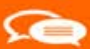

"ALIS has proven to be the industrial strength enterprise level policy administration platiorm wo had been searching for Wo have been able to internalize the ALIS conversion tools, helping us to be more self-sutncient and able to conduct the remaining conversions with less retiance on the Sapiens team Self sumciency was a key objective of our project and an important component of our originat ALIS evaluation criteria and selection decision.

STUART SMITH, IT VICE PRESIDENT, CFG

Source: $\underline{\text { http://www.sapiens.com/ }}$ 


\section{Exhibit 11: Sonata Bravura Solutions}

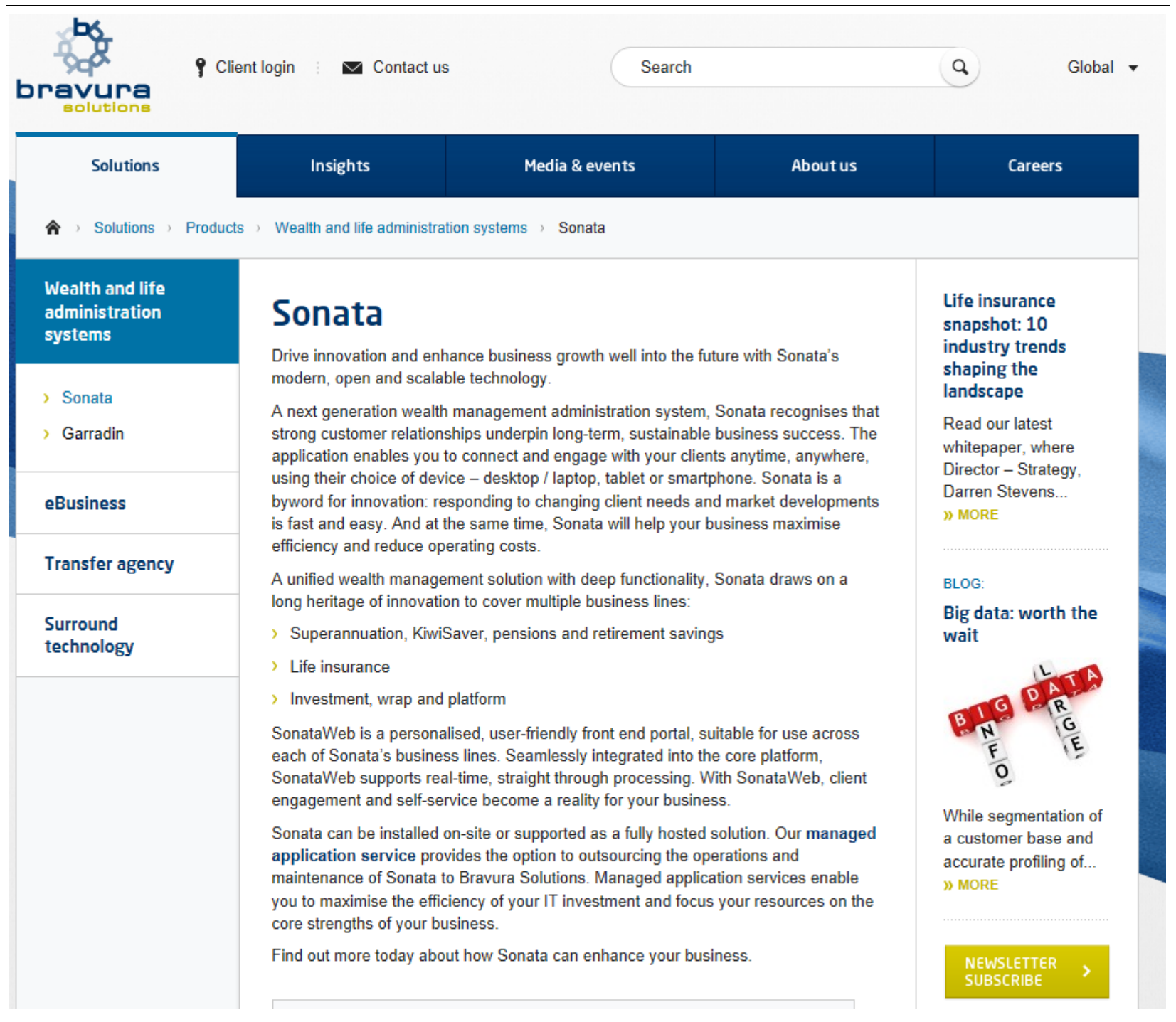

Source: http://bravurasolutions.com/ 
Exhibit 12: ORACLE Solutions

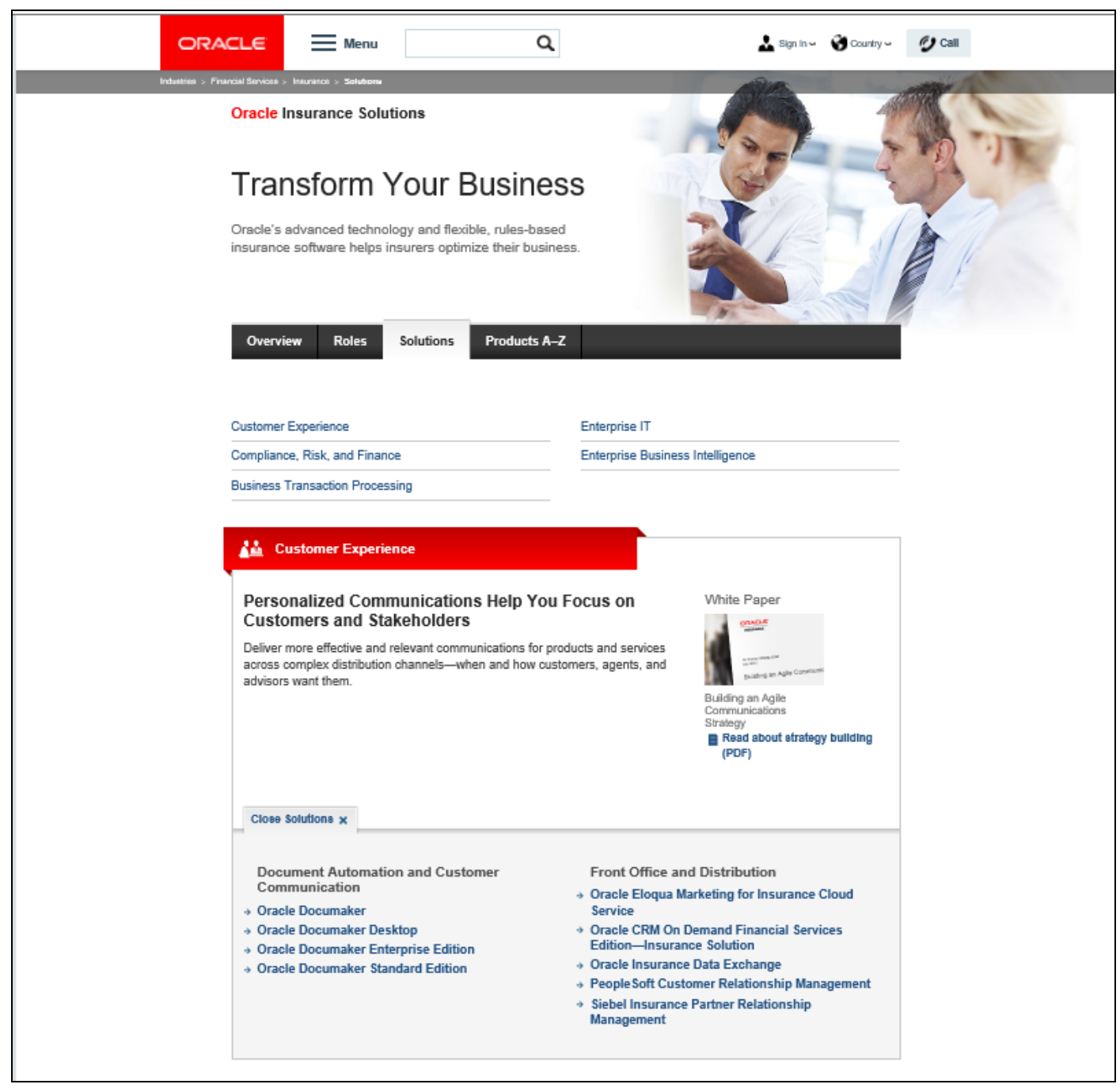

Source: https://www.oracle.com/industries/financial-services/insurance/solutions.html 
Exhibit 13: 4 Base Model for Migration

THERE ARE 4 BASE MODELS AND VARIATIONS FOR MOVING THE CURRENT POLICY BASE TO THE TARGET PLATFORM ....THE DETAILED WORK OUTLINED IN THE WAY FORWARD WILL DETAIL THE VALUE, COST AND RISK CASE TO DETERMINE THE BEST OPTION / MIX OF OPTIONS FOR CURRENT BOOKS OF BUSINESS AND THEIR ASSOCIATED POLICY/ BENEFIT STRUCTURES....

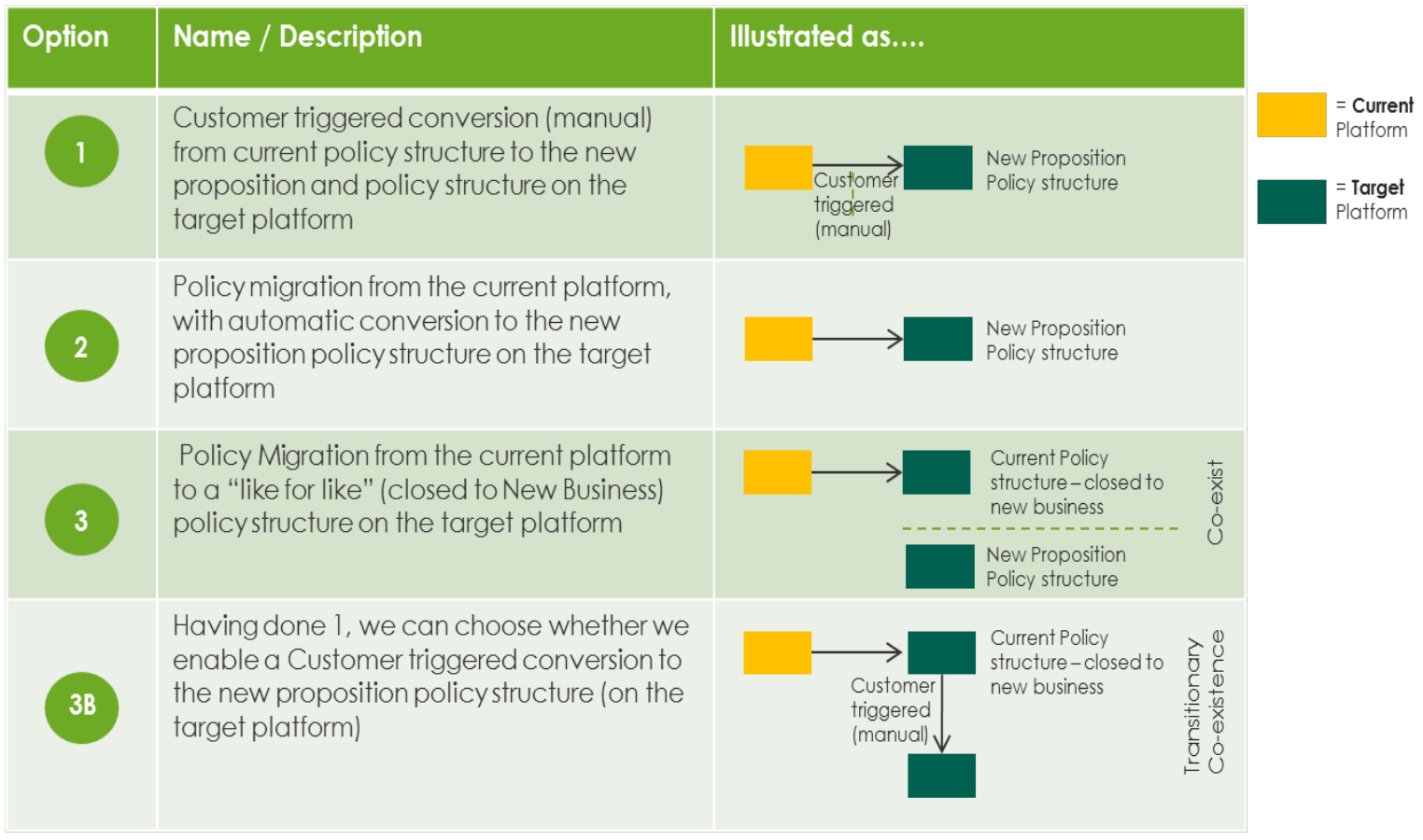

Source: Company internal website 